\title{
The association between gastro-oesophageal reflux and migraine in the paediatric population: a multicentre case-control study
}

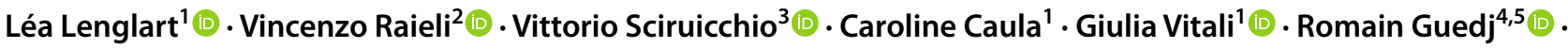

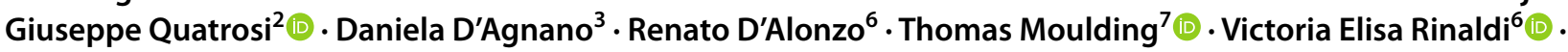 \\ Luigi Titomanlio ${ }^{1,8}$ (])
}

Received: 22 September 2021 / Revised: 23 December 2021 / Accepted: 26 December 2021 / Published online: 10 January 2022

(c) The Author(s), under exclusive licence to Springer-Verlag GmbH Germany, part of Springer Nature 2022

\begin{abstract}
Infantile regurgitation is one of the most common discomforts in the first months of life. Infantile colic and, in older children, functional dyspepsia have been linked to migraine. To date, this is the first study to investigate a possible association between infantile regurgitation and primary headaches in children. This is a case-control study of 195 children aged 6-17 years, with primary headache (migraine, or tension type headache) in 5 European paediatric hospitals. The control group is composed of 240 same-aged children attending with minor injuries during the same period — February 1st 2020 to December 1st 2020. A structured questionnaire identified a history of infantile regurgitation and other functional gastrointestinal disorders for case and control participants. The outcome was the difference in the prevalence of infantile regurgitation among children with or without a diagnosis of primary headache. The analysis showed a significant association between infantile regurgitation and migraine $(O R=1.88, C I 95=1.01-3.4$, $p=0.04)$. No association was found between infantile regurgitation and tension type headache $(p=0.33)$. Subgroup analysis confirmed that the association was only significant for migraine without aura $(O R=2.3, C I 95=1.2-4.4, p=0.01)$. In a further subgroup analysis, the presence of functional dyspepsia, irritable bowel syndrome and abdominal migraine was associated with migraine without aura.

Conclusion: The presence of migraine among children aged 6-17 was associated with a history of infantile regurgitation. Additional longitudinal studies are required to confirm whether infantile regurgitation could be considered as a precursor of migraine.

\section{What is Known:}

- Children suffering from functional gastrointestinal disorders are more likely to be suffering from migraine and tension-type headache as well.

- Children suffering from primary headache are more likely to have had infantile colic in their first six month of life.

What is New:

- It is the first study to find an association between migraine and infantile regurgitation in children.

- These findings could have an impact on the diagnosis and therapeutics of both migraine and infantile regurgitation.
\end{abstract}

Keywords Paediatric migraine · Infantile regurgitation · FGID

\section{Abbreviations}

AM Abdominal migraine

CVS Cyclic vomiting syndrome

CGRP Calcitonin gene-related peptide

FD Functional dyspepsia

\section{Communicated by Peter de Winter}

Léa Lenglart and Vincenzo Raieli contributed equally to this work.

Léa Lenglart

lea.lenglart@gmail.com

Extended author information available on the last page of the article
FGID Functional gastrointestinal disorders

IBS Irritable bowel syndrome

IC Infantile colic

ICHD-3 International Classification of Headache Disorders

MA Migraine with aura

MWA Migraine without aura

PACAP Pituitary Adenylate Cyclase-Activating Polypeptide

PED Pediatric emergency department

TTH Tension-type headache 


\section{Introduction}

Migraine is one of the most common types of primary headache. In the paediatric population, a recent epidemiological study [1] estimated the prevalence of migraine at $9.1 \%$, with cross-sectional studies underlying a constant increase in the incidence of migraine with and without aura [2].

Primary headaches are defined by the third edition of the International Classification of Headache Disorders (ICHD3) [3] and include migraine with or without aura and tension type headache as primary headaches, as well as trigeminal autonomic cephalalgias and other less common conditions. Nowadays, we acknowledge a wide spectrum of migrainerelated disorders. The ICHD-3 classifies abdominal migraine (AM), cyclic vomiting syndrome (CVS) and infantile colic (IC) as precursors of migraine [3]. Functional dyspepsia (FD) and irritable bowel syndrome (IBS) on the other hand have been linked to migraine in children by multiple studies [4-6]. These disorders have a great impact on the child's and parent's quality of life [7].

The relationship between migraine and functional gastrointestinal disorders (FGID) has been discussed at length in adults $[4,5,8]$ but much less so in the paediatric population [9]. FGID are defined as chronic and recurrent gastrointestinal symptoms that cannot be explained by an underlying clinical, biological or radiological abnormality. The pathophysiology of both FGID and migraine have been studied as possible disorders of the gut-brain axis [10]: abnormal findings concerning microbiota [11], the gut immune system [12] and gut innervation by sensory neurons [13] have been linked to the modulation of autonomic neurons, thus linking gut modifications to brain function modulation.

The Rome IV [14] criteria categorises the FGID in children/adolescents in three subtypes (Table 1):

- Functional abdominal pain disorders: FD, IBS, AM and functional abdominal pain — not otherwise specified
- Functional nausea and vomiting disorders: CVS, functional nausea and vomiting, rumination syndrome and aerophagia

- Functional defecation disorders: functional constipation and non-retentive faecal incontinence

In toddlers and newborns [15], seven functional gastrointestinal disorders have been described: infantile regurgitation, infantile rumination syndrome, CVS, IC, functional diarrhoea, infantile dyschezia and functional constipation. The most frequent FGID in toddlers is functional constipation [16], but thus far no link to migraine has been proven [9] between functional defecation disorders and migraine. To date, 3 studies have explored the epidemiological link between FGID and migraine in the paediatric population. Chelimsky et al. [17] found a relation between general FGID and migraine. Devanarayana et al. [18] and our group [9] found a relationship between FD, AM, CVS and migraine.

In 2013, we performed a case-control study of 679 patients which showed that children with migraine were 6.6 times more likely to have experienced IC $(\mathrm{p}<0.001)$ [19]. This hypothesis has since been supported by further researchers, allowing us to consider those phenomena as symptoms of the same spectrum [20].

Infantile regurgitation is a benign condition that occurs in $40-50 \%$ of infants, with a peak at 4 months of age [21]. It is considered to be a mechanical consequence of an immature lower oesophageal sphincter, allowing retrograde passage of gastric contents into the oesophagus, leading to a clinical regurgitation. Recurrent regurgitations can lead to gastro-oesophageal reflux disease (GORD), which is defined by the presence of complications such as haematemesis, melena, peptic oesophagitis, apnoea, apparent life-threatening events, laryngitis and otitis media. A clinical suspicion of GORD requires further investigation, such as oesophageal $\mathrm{pH}$ monitoring, and treatment with proton pump inhibitors (PPIs) when indicated.

Table 1 Rome IV Criteria of functional gastrointestinal disorders in children/adolescents and toddler/newborns

\begin{tabular}{|c|c|c|}
\hline & Toddler/newborns & Children/adolescents \\
\hline Functional abdominal pain disorders & -Infantile colic & $\begin{array}{l}\text {-Functional dyspepsia } \\
\text {-Irritable bowel syndrome } \\
\text {-Abdominal migraine } \\
\text {-Functional abdominal pain — not } \\
\text { otherwise specified }\end{array}$ \\
\hline Functional nausea and vomiting disorders & $\begin{array}{l}\text {-Infantile regurgitation } \\
\text {-Infantile rumination syndrome } \\
\text {-Cyclic vomiting syndrome }\end{array}$ & $\begin{array}{l}\text {-Cyclic vomiting syndrome } \\
\text {-Functional nausea and vomiting } \\
\text {-Rumination syndrome } \\
\text {-Aerophagia }\end{array}$ \\
\hline Functional defecation disorders & $\begin{array}{l}\text {-Functional diarrhoea } \\
\text {-Infantile dyschezia } \\
\text {-Functional constipation }\end{array}$ & $\begin{array}{l}\text {-Functional constipation } \\
\text {-Non-retentive faecal incontinence }\end{array}$ \\
\hline
\end{tabular}


To date, no studies have explored the potential link between infantile regurgitation and migraine. We formulate the hypothesis that infantile regurgitation may be part of the collective gut-brain axis disorders that may represent an early precursor of migraine.

\section{Methods}

\section{Study design and participants}

We performed a case-control study of children and adolescents in 5 European hospitals (Robert Debré, Paris, France; Armand Trousseau, Paris, France; Palermo, Italy; Bari, Italy; Foligno, Italy). We included all consecutive patients aged 6-17 years who were diagnosed with primary headaches migraine with aura (MA), migraine without aura (MWA) or tension-type headache (TTH) - by a paediatric neurologist in each centre, after a consultation relating to headache in the local paediatric emergency department (PED). Diagnoses were made using the validated ICHD-3 criteria [3]. Children with cluster headache, trigeminal autonomic cephalalgias and other primary headaches were excluded. Patients with a definite diagnosis of migraine were classified into the migraine group, regardless of the presence of concurrent TTH. For patients with migraine episodes with and without aura, they were classified as having MA.

Controls were consecutively enrolled children aged 6-17 who consulted the PED of 3 of the participating centres (Robert Debré and Armand Trousseau, Paris, France; Bari, Italy) for a minor injury in either the upper or the lower extremities, without cranial trauma, during the same period. Children with a history of recurrent headaches were excluded from the control group.

The inclusion period began on February 1st 2020 and ended on December 1st 2020. Inclusions were paused between March 15th and August 15th due to the effects of the COVID-19 pandemic on the healthcare systems in France and Italy.

Institutional ethical review boards at each centre approved the study protocol. There was no funding source for this study.

\section{Procedures}

Parents with their children were verbally questioned on the different components of the Rome IV [14, 15] diagnostic criteria for infantile regurgitation, IC, FD, CVS, IBS, AM and rumination. The questionnaire contained questions about demographic and medical information as well as several distractor questions. Case and control questionnaires can be found in the supplementary material.
When available, the health booklet (Carnet de santé in France, libretto sanitario in Italy) was screened by the physician to retrieve accurate medical information, in addition to that provided by the parents. These national booklets are given to parents soon after birth and contain medical data from birth to adulthood. The recorded data are the date of consultation, age, major clinical findings, diagnosis and therapy. Only physicians may write diagnoses in the health booklet. Thus, demographic data (age, gender, consanguinity, gestational age at birth and birth weight), co-existing medial disorders, presence of FGID and primary headache were obtained from both health booklets and parent's interviews. The health booklets were particularly useful to screen for infantile symptoms of IC or infantile regurgitation, which parents may have found difficult to accurately recall. Information about treatments (PPIs etc.) or feeding formulas that may have been prescribed in infancy could also be identified from the health booklet.

The presence of primary headaches in first degree relatives was assessed by interview only, as well as information on headache type for the case population (age at onset, frequency, clinical characteristics and therapeutic management).

\section{Definitions}

According to the Rome IV [15] criteria, in otherwise healthy infants of 3 weeks to 12 months of age, both of the following requirements must be met for a diagnosis of infantile regurgitation:

- Regurgitation two or more times per day for 3 or more weeks

- No retching, haematemesis, aspiration, apnoea, failure to thrive, feeding or swallowing difficulties or abnormal posturing

GORD is defined as the reflux of gastric contents, causing tissue damage and troublesome symptoms and/or complications such as weight loss or poor weight gain, irritability in infants, haematemesis, dysphagia, odynophagia, wheezing, stridor, cough, hoarseness, oesophagitis, recurrent pneumonia, feeding refusal, dystonic neck posturing (Sandifer syndrome), apnoeic spells and apparent life-threatening events.

We used the Rome IV $[14,15]$ criteria to define IC, rumination syndrome, CVS, IBS, FD and AM. The ICHD-3b definitions of migraine with and without aura and tensiontype headache were used to diagnose primary headache in our population [3]. Definitions used in the questionnaire can be found in the supplementary material.

\section{Statistical analysis}

We calculated the sample size on the basis of local admission frequencies for primary headaches in the study hospitals and 
with an expected frequency of infantile regurgitation of $20 \%$ in our control population. A sample size of 181 patients with primary headache and 362 control patients was calculated, with a power of $90 \%$ and a significance lever of 0.05 in a twotailed test. The primary outcome measure was the difference in prevalence of infantile regurgitation between children with migraine and participants without a diagnosis of primary headache. The specificity of this association was assessed by comparing the prevalence of infantile regurgitation in children with TTH with that of the control group. We compared categorical variables between groups with the $\chi 2$ analysis and continuous non-Gaussian variables with the Wilcoxon analysis.

Univariable and multivariable analyses were carried out to identify factors associated with migraines and tension type headache. We then used a multivariable logistic regression model with the backward stepwise method to identify factors independently associated with migraine, and odds ratios (OR) and their 95\% confidence intervals (CIs) were calculated. All tests were two-tailed with a 0.05 significance level.

To determine whether infantile regurgitation was associated with a specific migraine subgroup, we did a comparative analysis between patients with MA and those with MWA. To determine whether infantile regurgitation was associated to clinical characteristics of migraine, we performed a comparative analysis between patients with or without infantile regurgitation in the migraine group.

\section{Results}

Between February 1st and December 1st 2020, 195 cases of primary headaches and 240 controls were enrolled. A total of 168 patients had migraine (38\%), of whom 139 (82\%) had MWA and 29 (18\%) had MA, and 27 cases had TTH (6\%).

Clinical characteristics of enrolled patients at baseline are shown in Table 2. A significant difference was observed concerning gender, birthweight, comorbidity and family history of migraine in first degree relatives of patients with migraine.

The prevalence of FGID in the studied population is shown in Table 3.

A total of 64 (37.9\%) migraineurs had a personal history of infantile regurgitation, compared to $45(18.8 \%)$ in the control group $(\mathrm{p}<0.001)$. This association was not shown in children with TTH $(p=0.5)$. When analysing migraine subgroups, the prevalence of infantile regurgitation was only significant in children with MWA (40.3\%, $\mathrm{p}<0.001$ versus $27.6 \%(\mathrm{p}=0.4)$ in MA). All the FGID analysed in the study were significantly more prevalent in migraineurs when compared to controls. On the other hand, no significant difference was identified when comparing children suffering from TTH and control patients.
Variables significantly associated with migraines or TTH in multivariable analysis are shown in Table 4 . The subgroup analysis for MWA and MA is shown in Table 5.

The male sex was a protective factor for migraine $(\mathrm{OR}=0.54$, CI $95=0.3-0.9, \mathrm{p}=0.02)$ but not for TTH $(p=0.15)$. Subgroup analysis found that it was also protective for MA $(\mathrm{OR}=0.21$, CI $95=0.06-0.6, \mathrm{p}=0.004)$ but not for MWA $(\mathrm{p}=0.18)$.

The presence of a family history of migraine in firstdegree relatives increased the risk of migraine $(\mathrm{OR}=12.4$, CI $95=7.2-22.0, p<0.001$ ) either with or without aura. This was not observed in the TTH population $(\mathrm{OR}=2.1$, CI $95=0.7-6.0, p=0.15$ ).

The analysis confirmed a significant association between infantile regurgitation and migraine $(\mathrm{OR}=1.88$, CI $95=1.01-3.4, p=0.04)$. No association was found between infantile regurgitation and TTH $(p=0.33)$. Subgroup analysis confirmed that the association was only significant for MWA $(\mathrm{OR}=2.3$, CI $95=1.2-4.4, \mathrm{p}=0.01)$.

Among the other FGID, a significant association was found for $\mathrm{FD}(\mathrm{OR}=19.8$, CI 95 $=3.4-382.1, \mathrm{p}=0.006)$, for IBS $(\mathrm{OR}=8.9$, CI $95=2.0-65.2, \mathrm{p}=0.01)$ and for AM $(\mathrm{OR}=15.8$, CI 95 = 5.0-61.3, $\mathrm{p}=<0.001)$; whereas TTH was associated with FD (OR $=94$, CI $95=12.7-1966.2$, $\mathrm{p}=<0.001)$ and IBS $(\mathrm{OR}=34.7$, CI $95=5.8-285.3$, $\mathrm{p}=<0.001)$. In the subgroup analysis, the presence of FD, IBS and AM was associated with MWA, while AM was significantly associated only with $\mathrm{MA}(\mathrm{OR}=39$, CI $95=7.9-244.9, \mathrm{p}=<0.001)$.

With respect to migraineur behaviour, the only difference established between the two groups was that children presenting with infantile regurgitation were more likely to use pre-emptive migraine treatments than those who did not $(46.9 \%$ versus $22.9 \%, \mathrm{p}=0.002)$.

\section{Discussion}

Our study is the first to show a link between personal history of infantile regurgitation and migraine in a paediatric population. We did not find any significant association between infantile regurgitation and TTH. The subgroup analysis found a significant association between infantile regurgitation and MWA, which is observed more frequently than MA in children [22].

In our study, among FGID, only FD, IBS and AM were associated with migraine, confirming previous findings. Indeed, the relation between FD, IBS, AM and migraine in the paediatric population has already been reported by our team [9]. We did not find any association between CVS and migraine. Devanarayana et al. [18] also found a significant relation between FD, IBS, AM and migraine in a cross-sectional survey of 2180 children living in Sri Lanka. 
Table 2 Children characteristics at baseline

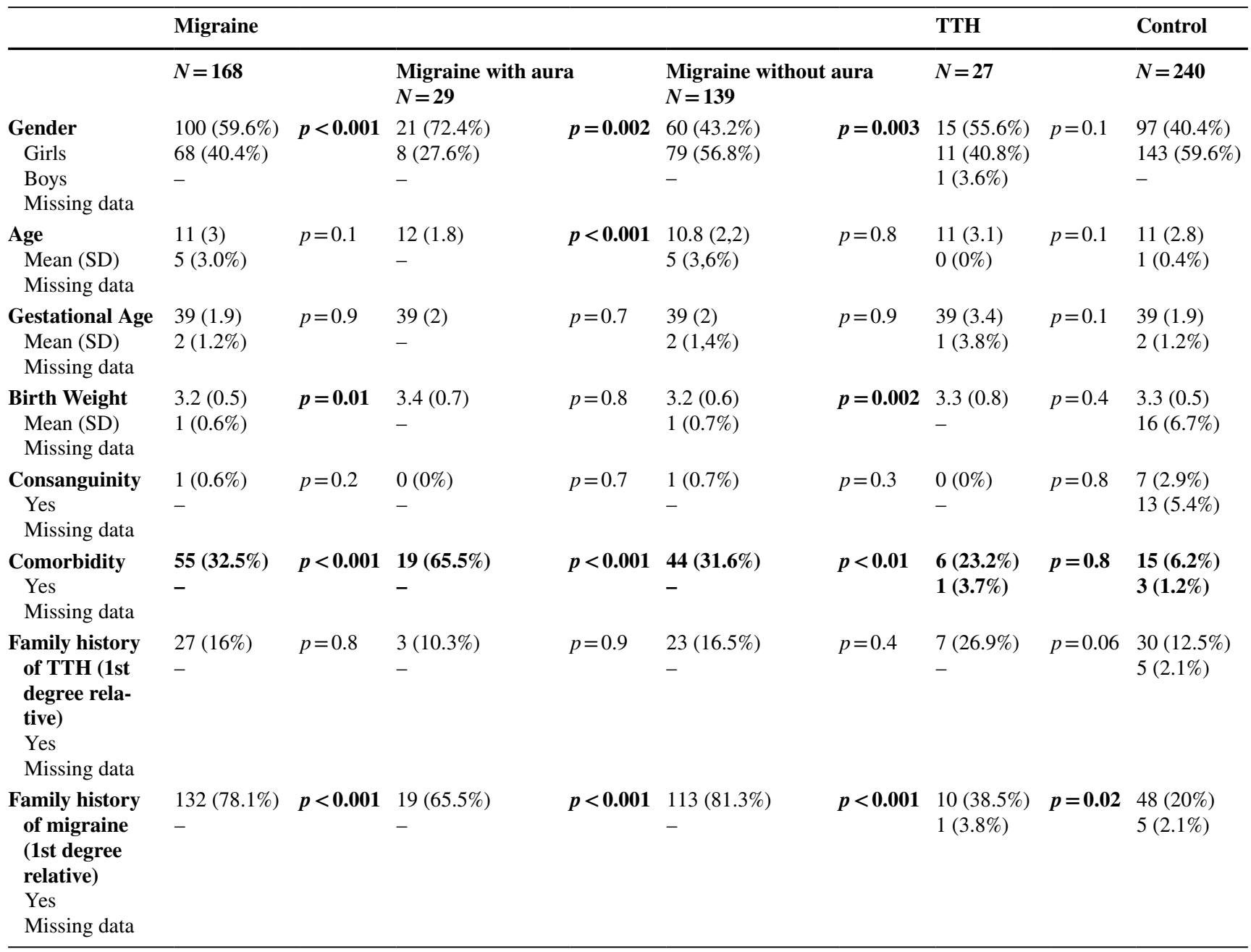

$p$-values for chi-2 test (binary variables) and Wilcoxon test (continuous variables) with $\alpha=5 \%$

Lankarani et al. [4] confirmed increased ORs of 3.43 for IBS and 1.68 for FD in the adult migraineur population.

The relationship between FD and TTH has been previously reported in the adult population, and Tai et al. [23] also highlighted an increase in TTH symptoms in adult patients suffering from functional dyspepsia. Martami et al. [24] found results consistent with ours, showing a significant relation between FD and TTH, and a significant relation between FD, IBS and migraine in a cross-sectional study of 1574 adult participants.

The relationship between FGID and the migraine subtypes has rarely been explored in the literature; however, we have previously reported [9] a significant association between AM and MA, and an association between FD, IBS, AM and MWA. Another group reported that the association between IBS and MWA in young women was found to be related to a greater incidence of fibromyalgia and anxiety disorders [25]. Furthermore, we found that children requiring pre-emptive migraine treatment were more likely to have experienced infantile regurgitation. We speculate that infantile regurgitation may predispose to a more severe form of migraine, although this needs further confirmation.

We have investigated the hypothesis that the multifactorial phenomena linking infantile colic and functional dyspepsia with migraine is similar to the association of infantile regurgitation with migraine. The many different pathophysiological pathways of the gut-brain axis have been recently explored in a review, summarising the recent knowledge on abdominal variants of migraine and functional abdominal pain disorders associated with migraine in the paediatric population [26]. Gastric motility abnormalities, impaired gastric accommodation and visceral hypersensitivity are all related to functional dyspepsia and migraine, and could be key to a better understanding of infantile regurgitation. Furthermore, the pathophysiological hypothesis concerning infantile colic also includes visceral hypersensitivity and inflammatory mediation secondary to modifications of the 
Table 3 Prevalence of functional gastrointestinal disorders in our population: infantile regurgitation, infantile colic, functional dyspepsia, rumination syndrome, cyclic vomiting syndrome, irritable bowel syndrome and abdominal migraine

\begin{tabular}{|c|c|c|c|c|c|c|c|c|c|}
\hline & Migraine & & & & & & TTH & & Control \\
\hline & $N=168$ & & $\begin{array}{l}\text { Migraine with aura } \\
N=29\end{array}$ & & $\begin{array}{l}\text { Migraine w } \\
\text { aura } \\
N=139\end{array}$ & thout & $N=\mathbf{2 7}$ & & $N=\mathbf{2 4 0}$ \\
\hline $\begin{array}{l}\text { Infantile regurgita- } \\
\text { tion } \\
\text { Yes } \\
\text { Missing data }\end{array}$ & $\begin{array}{l}64(37.9 \%) \\
-\end{array}$ & $p<0.001$ & $\begin{array}{l}8(27.6 \%) \\
-\end{array}$ & $p=0.4$ & $\begin{array}{l}56(40.3 \%) \\
-\end{array}$ & $p<0.001$ & $\begin{array}{l}7(26.9 \%) \\
-\end{array}$ & $\mathrm{p}=0.5$ & $\begin{array}{l}45(18.8 \%) \\
1(0.4 \%)\end{array}$ \\
\hline $\begin{array}{l}\text { Type of infantile } \\
\text { regurgitation } \\
\text { Reflux } \\
\text { GORD } \\
\text { Missing data }\end{array}$ & $\begin{array}{l}50(29.7 \%) \\
14(8.3 \%) \\
-\end{array}$ & $p<0.001$ & $\begin{array}{l}6(20.7 \%) \\
2(6.9 \%) \\
-\end{array}$ & $p=0.02$ & $\begin{array}{l}44(31.6 \%) \\
12(8.6 \%) \\
-\end{array}$ & $p<0.001$ & $\begin{array}{l}6(22.2 \%) \\
1(3.7 \%) \\
-\end{array}$ & $p=0.09$ & $\begin{array}{l}44(18.3 \%) \\
1(0.4 \%)\end{array}$ \\
\hline $\begin{array}{l}\text { Infantile Colic } \\
\text { Yes } \\
\text { Missing data }\end{array}$ & $\begin{array}{l}87(51.5 \%) \\
-\end{array}$ & $p<0.001$ & $\begin{array}{l}15(51.7 \%) \\
-\end{array}$ & $p<0.001$ & $\begin{array}{l}72(51.8 \%) \\
-\end{array}$ & $p<0.001$ & $\begin{array}{l}10(38.5 \%) \\
-\end{array}$ & $p=0.6$ & $\begin{array}{l}70(29.2 \%) \\
3(1.2 \%)\end{array}$ \\
\hline $\begin{array}{l}\text { Functional Dyspep- } \\
\text { sia } \\
\text { Yes } \\
\text { Missing data }\end{array}$ & $\begin{array}{l}27(16 \%) \\
-\end{array}$ & $p<0.001$ & $\begin{array}{l}3(10.3 \%) \\
-\end{array}$ & $p<0.001$ & $\begin{array}{l}24(17.2 \%) \\
-\end{array}$ & $p<0.001$ & $\begin{array}{l}6(23.1 \%) \\
-\end{array}$ & $p<0.001$ & $\begin{array}{l}1(0.4 \%) \\
3(1.2 \%)\end{array}$ \\
\hline $\begin{array}{l}\text { Rumination syn- } \\
\text { drome } \\
\text { Yes } \\
\text { Missing data }\end{array}$ & $\begin{array}{l}14(8.3 \%) \\
-\end{array}$ & $p<0.001$ & $\begin{array}{l}2(6.9 \%) \\
-\end{array}$ & $p<0.001$ & $\begin{array}{l}12(8.6 \%) \\
-\end{array}$ & $p<0.001$ & $\begin{array}{l}1(3.8 \%) \\
-\end{array}$ & $p=0.5$ & $\begin{array}{l}1(0.4 \%) \\
2(0.8 \%)\end{array}$ \\
\hline $\begin{array}{l}\text { Cyclic Vomiting } \\
\text { Syndrome } \\
\text { Yes } \\
\text { Missing data }\end{array}$ & $\begin{array}{l}7(4.1 \%) \\
-\end{array}$ & $p=0.02$ & $\begin{array}{l}1(3.4 \%) \\
-\end{array}$ & $p=0.5$ & $\begin{array}{l}6(4.3 \%) \\
-\end{array}$ & $p=0.02$ & $\begin{array}{l}0(0 \%) \\
-\end{array}$ & $p=1$ & $\begin{array}{l}1(0.4 \%) \\
3(1.2 \%)\end{array}$ \\
\hline $\begin{array}{l}\text { Irritable Bowel } \\
\text { Syndrome } \\
\text { Yes } \\
\text { Missing data }\end{array}$ & $\begin{array}{l}25(14.8 \%) \\
1(0.6 \%)\end{array}$ & $p<0.001$ & $\begin{array}{l}2(6.9 \%) \\
-\end{array}$ & $p=0.2$ & $\begin{array}{l}23(16.5 \%) \\
1(0.8 \%)\end{array}$ & $p<0.001$ & $\begin{array}{l}5(19.2 \%) \\
-\end{array}$ & $p<0.001$ & $\begin{array}{l}3(1.2 \%) \\
3(1.2 \%)\end{array}$ \\
\hline $\begin{array}{l}\text { Abdominal Migraine } \\
\text { Yes } \\
\text { Missing data }\end{array}$ & $\begin{array}{l}33(19.5 \%) \\
-\end{array}$ & $p<0.001$ & $\begin{array}{l}8(27.6 \%) \\
-\end{array}$ & $p<0.001$ & $\begin{array}{l}25(18.0 \%) \\
-\end{array}$ & $p<0.001$ & $2(7.7 \%)$ & $p=0.3$ & $\begin{array}{l}5(2.1 \%) \\
3(1.2 \%)\end{array}$ \\
\hline
\end{tabular}

$p$-values for chi-2 test (binary variables) with $\alpha=5 \%$

Table 4 Multivariable logistic regression of infantile regurgitation and covariables for migraine or tension type headache

\begin{tabular}{|c|c|c|c|c|c|c|}
\hline & \multicolumn{3}{|c|}{$\begin{array}{l}\text { Migraine } \\
N=168\end{array}$} & \multicolumn{3}{|c|}{$\begin{array}{l}\text { Tension type headache } \\
N=27\end{array}$} \\
\hline & $O R$ & CI 95\% & $p$-val & $O R$ & CI 95\% & $p$-val \\
\hline Infantile regurgitation & 1.88 & $1.01-3.4$ & 0.04 & 1.7 & $0.5-5.07$ & 0.33 \\
\hline Gender & 0.54 & $0.3-0.9$ & 0.02 & 0.47 & $0.1-1.3$ & 0.15 \\
\hline $\begin{array}{l}\text { Family history of migraine } \\
\text { (1st degree) }\end{array}$ & 12.4 & $7.2-22.0$ & $<0.001$ & 2.1 & $0.7-6.0$ & 0.15 \\
\hline Functional dyspepsia & 19.8 & $3.4-382.1$ & 0.006 & 94.0 & $12.7-1966.2$ & $<0.001$ \\
\hline Irritable bowel syndrome & 8.9 & $2.0-65.2$ & 0.01 & 34.7 & $5.8-285.3$ & $<0.001$ \\
\hline Abdominal migraine & 15.8 & $5.0-61.3$ & $<0.001$ & 5.3 & $0.6-31.7$ & 0.07 \\
\hline
\end{tabular}

$p$-values for $\alpha=5 \%$ 
Table 5 Multivariable logistic regression of infantile regurgitation and covariables for subgroup analysis: migraine with and without aura

\begin{tabular}{|c|c|c|c|c|c|c|}
\hline & \multicolumn{3}{|c|}{$\begin{array}{l}\text { Migraine with aura } \\
N=29\end{array}$} & \multicolumn{3}{|c|}{$\begin{array}{l}\text { Migraine without aura } \\
N=139\end{array}$} \\
\hline & $O R$ & CI $95 \%$ & $p$-val & $O R$ & CI 95\% & $p$-val \\
\hline Infantile regurgitation & 0.98 & $0.2-2.9$ & 0.97 & 2.3 & $1.2-4.4$ & 0.01 \\
\hline Gender & 0.21 & $0.06-0.6$ & 0.004 & 0.67 & $0.3-1.2$ & 0.12 \\
\hline $\begin{array}{l}\text { Family history of migraine } \\
\text { (1st degree) }\end{array}$ & 8.6 & $3.1-25.2$ & $<0.001$ & 14.3 & $7.9-27.1$ & $<0.001$ \\
\hline Functional dyspepsia & 9.8 & $0.5-275.3$ & 0.12 & 26.3 & $4.2-525.0$ & 0.03 \\
\hline Irritable bowel syndrome & 1.9 & $0.1-36.4$ & 0.63 & 10.7 & $2.4-79.1$ & 0.05 \\
\hline Abdominal migraine & 39 & $7.9-244.9$ & $<0.001$ & 11.2 & $3.2-46.7$ & $<0.001$ \\
\hline
\end{tabular}

$p$-values for $\alpha=5 \%$ gut microbiome. The factors influencing the microbiota of children and their mothers has been widely explored to better understand infantile colic. These phenomena may be intrinsic to the link between infantile regurgitation and migraine highlighted in this study.

The pathophysiology of migraine is also a multifactorial phenomenon [27] dependent on genetic factors (more than thirty migraine-associated gene polymorphisms have been discovered [28]), environmental factors (such as medication, diet and stress) and metabolic factors (examples include neuroendocrine function, the menstrual cycle and pregnancy). The activation of the hypothalamus results in an alteration in thalamo-cortical circuits and brain connectivity, which subsequently leads to CGRP (calcitonin gene-related peptide) and PACAP (pituitary adenylate cyclase-activating polypeptide) release. The release of PACAP triggers intracerebral vasodilatation, ultimately causing the symptoms of migraine. Today, the role of CGRP in the bidirectional communication of the gut-brain axis is well recognised: CGRP has an antimicrobial action on gut bacterial strains (for instance Escherichia coli, Enterococcus faecalis and Lactobacillus acidophilus) and dysbiosis can increase the secretion of CGRP [10]. Supporting this knowledge, studies have recently suggested a benefit in providing probiotics in the management of infantile colic [29] and IBS [30]. The communication of the gut's immune system, mucosa and microbiota with the brain has been explored in great depth within the field of migraine research, particularly the association between functional abdominal pain syndromes and migraine [10].

Our study has some limitations; as a case-control study, it is subject to many biases. Firstly, we decided to enrol the cases from consultations with a paediatric neurologist whereas the control population was sourced from PEDs. It is likely that patients with primary headache were more severe than in the general population, hence having been referred to a paediatric neurologist. Indeed, we observed that $32.5 \%$ of the migrainous patients and $23.2 \%$ of TTH patients had comorbidities, whereas this figure was $6.2 \%$ in the control population. Therefore, the sample may not be representative of the general population; however, similar studies have also observed a higher prevalence of comorbidities among patients attending neurology clinics $[9,19]$. Secondly, we tried to minimise the impact of possible response bias in this study. Indeed, we did not inform the parents or the child about the hypothesis tested in this study; they were merely asked to answer a questionnaire on migraine and pain syndromes, and distractors were added to the questionnaire. Moreover, in order to reduce the memory bias due to the retrospective design of the study, we used both the parents' questionnaire and the health booklet to assess for infantile symptoms, FIGD and primary headaches. One could also argue that parents may tend to give more precise answers to a paediatric neurologist than the PED physician. However, we concluded that the answers would be subject to less bias when the questionnaire was filled out by the same physician who cared for the child, rather than waiting for another physician. Furthermore, we used validated international classifications of FGID and migraine, allowing the responses to be easily comparable. Finally, the number of controls subjects enrolled is less than expected. Indeed, we had to stop the study for 6 months during the first wave of the COVID-19 pandemic. Moreover, the pandemic had a drastic impact on the attendance rate of PED in France and in Italy [31], thus hampering the enrolment of control patients. However, as the required number of subjects was calculated prior to the study, we agreed to stop including participants into the study on December 1st, 2020. To avoid the response bias, a prospective longitudinal study with follow-up from birth to adolescence would be necessary, although implementation would be challenging, and due to the method of enrolment, there is a high chance of many patients being lost to follow up. Moreover, this study was designed as a pilot study, to test the hypothesis of a relation between infantile regurgitation and migraine in the paediatric population.

In conclusion, in a multicentre case-control study, we established a significant association between infantile regurgitation and migraine. The subgroup analysis showed a significant association between MWA and infantile regurgitation only. Interestingly, we did not find any association 
between infantile regurgitation and TTH, thus suggesting these findings are specific to migraine. Our results support the growing body of evidence of a common pathophysiological pathway between FGID and migraine. Clinically, these findings could have an impact on the diagnosis and therapeutic management of these common diseases, especially in the paediatric population.

Supplementary information The online version contains supplementary material available at https://doi.org/10.1007/s00431-021-04368-6.

Authors' contributions Léa Lenglart*: conceptualization and design of the study, analysis and interpretation of the data and drafting the article. Vincenzo Raieli* : conceptualization and design of the study, analysis and interpretation of the data and critically revising the article. Vittorio Sciruicchio: conceptualization and design of the study, acquisition of data, interpretation of data and critically revising the article. Caroline Caula: literature search, acquisition of data and drafting the article. Giulia Vitali: literature search, acquisition of data and drafting the article. Romain Guedj: acquisition of data, interpretation of data and revising for important intellectual content. Giuseppe Quatrosi: acquisition of data and revising for important intellectual content. Daniela D'Agnano: acquisition of data and revising for important intellectual content. Renato D'Alonzo: acquisition of data and revising for important intellectual content. Thomas Moulding: interpretation of data and critically revising the article. Victoria Elisa Rinaldi: literature search, acquisition of data and critically revising the article. Luigi Titomanlio: conceptualization and design of the study, coordinating and supervising data collection and critically revising the article. All authors approved the final manuscript as submitted and agree to be accountable for all aspects of the work.

\section{Availability of data and material Yes.}

Code availability Yes.

\section{Declarations}

Ethics approval Yes.

Consent to participate Informed consent.

Consent for publication Informed consent

Conflict of interest The authors declare no competing interests

\section{References}

1. Wöber-Bingöl Ç (2013) Epidemiology of migraine and headache in children and adolescents. Curr Pain Headache Rep 17(6):341

2. Anttila P (2006) Long-term Trends in the incidence of headache in Finnish schoolchildren. Pediatrics 117(6):e1197-e1201

3. Headache Classification Committee of the International Headache Society (IHS) (2018) The international classification of headache disorders, 3rd edition. Cephalalgia 38:1-211

4. Lankarani KB, Akbari M, Tabrizi R (2017) Association of gastrointestinal functional disorders and migraine headache: a population base study. Middle East J Dig Dis 9(3):139-145
5. van Hemert S, Breedveld AC, Rovers JMP, Vermeiden JPW, Witteman BJM, Smits MG et al (2014) Migraine associated with gastrointestinal disorders: review of the literature and clinical implications. Front Neurol 2014 Nov 21 [cited 2019 Feb 27]5. Available from: http://journal.frontiersin.org/article/10.3389/ fneur.2014.00241/abstract

6. Kumagai H, Yokoyama K, Imagawa T, Yamagata T (2016) Functional dyspepsia and irritable bowel syndrome in teenagers: internet survey: FD and IBS in early teens. Pediatr Int 58(8):714-720

7. Koller LS, Diesner SC, Voitl P (2019) Quality of life in children and adolescents with migraine: an Austrian monocentric, crosssectional questionnaire study. BMC Pediatr 19(1):164

8. Cole JA, Rothman KJ, Cabral HJ, Zhang Y, Farraye FA (2006) Migraine, fibromyalgia, and depression among people with IBS: a prevalence study. BMC Gastroenterol 28(6):26

9. Le Gal J, Michel J-F, Rinaldi VE, Spiri D, Moretti R, Bettati D et al (2016) Association between functional gastrointestinal disorders and migraine in children and adolescents: a case-control study. Lancet Gastroenterol Hepatol 1(2):114-121

10. Arzani M, Jahromi SR, Ghorbani Z, Vahabizad F, Martelletti P et al (2020) Gut-brain Axis and migraine headache: a comprehensive review. J Headache Pain (1):15

11. Raskov H, Burcharth J, Pommergaard H-C, Rosenberg J (2016) Irritable bowel syndrome, the microbiota and the gut-brain axis. Gut Microbes 7(5):365-383

12. Elsenbruch S (2011) Abdominal pain in irritable bowel syndrome: a review of putative psychological, neural and neuro-immune mechanisms. Brain Behav Immun 25(3):386-394

13. Leuchter RH-V, Darque A, Hüppi PS (2013) Brain maturation, early sensory processing, and infant colic: J Pediatr Gastroenterol Nutr S18-25

14. Hyams JS, Di Lorenzo C, Saps M, Shulman RJ, Staiano A, van Tilburg M (2016) Childhood functional gastrointestinal disorders: child/adolescent. Gastroenterology 150(6):1456-1468.e2

15. Benninga MA, Faure C, Hyman PE, St James Roberts I, Schechter NL, Nurko S (2016) Childhood functional gastrointestinal disorders: neonate/toddler. Gastroenterology

16. Steutel NF, Zeevenhooven J, Scarpato E, Vandenplas Y, Tabbers MM, Staiano A et al (2020) Prevalence of functional gastrointestinal disorders in European infants and toddlers. J Pediatr 221:107-114

17. Chelimsky G, Safder S, Chelimsky T (2012) FGIDs in children are associated with many nonpsychiatric comorbidities: the tip of an iceberg? J Pediatr Gastroenterol Nutr 54(5):690-691

18. Devanarayana NM, Mettananda S, Liyanarachchi C, Nanayakkara N, Mendis N, Perera N et al (2011) Abdominal pain-predominant functional gastrointestinal diseases in children and adolescents: prevalence, symptomatology, and association with emotional stress. J Pediatr Gastroenterol Nutr 53(6):659-665

19. Romanello S, Spiri D, Marcuzzi E, Zanin A, Boizeau P, Riviere S et al (2013) Association between childhood migraine and history of infantile colic. JAMA 309(15):1607-1612

20. Qubty W, Gelfand AA (2016) The link between infantile colic and migraine. Curr Pain Headache Rep 20(5):31

21. Leung AK, Hon KL (2019) Gastroesophageal reflux in children: an updated review. Drugs Context 8:212591

22. Lewis DW (2007) Pediatric migraine. Pediatr Rev 28(2):43-53

23. Tai MLS, Norhatta N, Goh KJ, Moy FM, Sujarita R, Asraff AA et al The impact of dyspepsia on symptom severity and quality of life in adults with headache. PloS One 10(1):e0115838

24. Martami F, Ghorbani Z, Abolhasani M, Togha M, Meysamie A, Sharifi A et al (2018) Comorbidity of gastrointestinal disorders, migraine, and tension-type headache: a cross-sectional study in Iran. Neurol Sci Off J Ital Neurol Soc Ital Soc Clin Neurophysiol 39(1):63-70 
25. Georgescu D, Reisz D, Gurban CV, Georgescu L, Ionita I, Ancusa OE et al (2017) Migraine in young females with irritable bowel syndrome: still a challenge. Neuropsychiatr Dis Treat 14:21-28

26. LenglarT L, Caula C, Moulding T, Lyles A, Wohrer D, Titomanlio L (2021) Brain to belly: abdominal variants of migraine and functional abdominal pain disorders associated with migraine. $\mathbf{J}$ Neurogastroenterol Motil 27(4):482-494

27. Charles A (2018) The pathophysiology of migraine: implications for clinical management. Lancet Neurol 17(2):174-182

28. International Headache Genetics Consortium, Gormley P, Anttila V, Winsvold BS, Palta P, Esko T et al (2016) Meta-analysis of 375,000 individuals identifies 38 susceptibility loci for migraine. Nat Genet 48(8):856-66

29. Sung V, D’Amico F, Cabana MD, Chau K, Koren G, Savino F et al (2018) Lactobacillus reuteri to treat infant colic: a meta-analysis. Pediatrics 141(1):e20171811
30. Newlove-Delgado TV, Martin AE, Abbott RA, Bethel A, ThompsonCoon J, Whear R et al (2017) Dietary interventions for recurrent abdominal pain in childhood. Cochrane Developmental, Psychosocial and Learning Problems Group, editor. Cochrane Database Syst Rev [Internet] [cited 2021 Jan 28] Available from: http://doi.wiley.com/10.1002/14651858.CD010972.pub2

31. Kruizinga MD, Peeters $D$, van Veen $M$, van Houten $M$, Wieringa J, Noordzij JG et al (2021) The impact of lockdown on pediatric ED visits and hospital admissions during the COVID-19 pandemic: a multicenter analysis and review of the literature. Eur J Pediatr [Internet] [cited 2021 Mar 19] Available from: http://link. springer.com/10.1007/s00431-021-04015-0

Publisher's Note Springer Nature remains neutral with regard to jurisdictional claims in published maps and institutional affiliations.

\section{Authors and Affiliations}

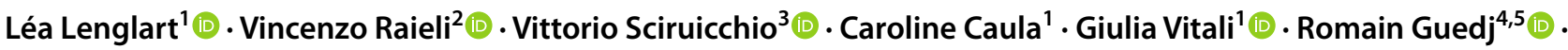 Giuseppe Quatrosi ${ }^{2}$ (D) Daniela D'Agnano ${ }^{3} \cdot$ Renato D'Alonzo $^{6}$. Thomas Moulding ${ }^{7}$ (1) - Victoria Elisa Rinaldi ${ }^{6}$ (D) Luigi Titomanlio ${ }^{1,8}$}

Vincenzo Raieli

v.raieli@alice.it

Vittorio Sciruicchio

vsciru@tin.it

Caroline Caula

carolinecaula@hotmail.fr

Giulia Vitali

giulia_vitali@live.com

Romain Guedj

romain.guedj@aphp.fr

Giuseppe Quatrosi

peppe.quatrosi@gmail.com

Daniela D'Agnano

daniela.dagnano@gmail.com

Renato D'Alonzo

renato.dalonzo@uslumbria2.it

Thomas Moulding

thomas.moulding@nhs.net

Victoria Elisa Rinaldi

victoria.rinaldi87@gmail.com
Luigi Titomanlio

luigi.titomanlio@aphp.fr

1 Department of Paediatric Emergency Care, DM'UP, APHP, Hôpital Robert Debré, 48 Boulevard Serrurier, Paris 75019, France

2 Child Neuropsychiatry Unit, ISMEP, ARNAS Civico, Palermo, Italy

3 Children Epilepsy and EEG Centre, S. Paolo Hospital, Bari, Italy

4 Department of Paediatric Emergency Care, Hôpital Armand Trousseau, APHP, Paris 75012, France

5 Faculté de Médecine, UMR153, Sorbonne Université, Paris, Inserm, France

6 Department of Paediatrics, Ospedale S. Giovanni Battista, Foligno 06034, Italia

7 Department of Specialty and Integrated Medicine, Leeds Teaching Hospitals Trust, Leeds, UK

8 University of Paris, HU I2D2 INSERM UMR1141 Paris, France 